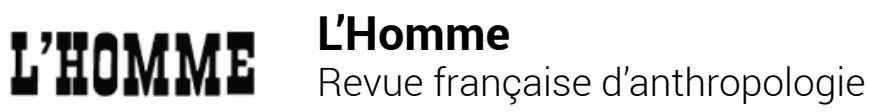

175-176 | juillet-septembre 2005

Vérités de la fiction

\section{Pierre Duviols, ed, Procesos y Visitas de Idolatrías, Cajatambo Siglo XVII}

Lima, Institut français d'études andines - Fondo editorial de la Pontificia Universidad Católica del Perú, 2003, 882 pages

Valérie Robin

\section{OpenEdition}

1 Journals

Édition électronique

URL : http://journals.openedition.org//homme/2063

DOI : 10.4000/lhomme.2063

ISSN : 1953-8103

Éditeur

Éditions de l'EHESS

Édition imprimée

Date de publication : 15 octobre 2005

Pagination : 524-528

ISBN : 2-7132-2035-1

ISSN : 0439-4216

Référence électronique

Valérie Robin, «Pierre Duviols, ed, Procesos y Visitas de Idolatrías, Cajatambo Siglo xVII », L'Homme [En ligne], 175-176 | juillet-septembre 2005, mis en ligne le 30 novembre 2006, consulté le 24 septembre 2020. URL : http://journals.openedition.org//homme/2063 ; DOI : https://doi.org/10.4000/lhomme. 2063

Ce document a été généré automatiquement le 24 septembre 2020.

(c) École des hautes études en sciences sociales 


\section{Pierre Duviols, ed, Procesos y Visitas de Idolatrías, Cajatambo Siglo XVII}

Lima, Institut français d'études andines - Fondo editorial de la Pontificia Universidad Católica del Perú, 2003, 882 pages

\section{Valérie Robin}

\section{RÉFÉRENCE}

Pierre Duviols, ed. Procesos y Visitas de Idolatrías, Cajatambo Siglo XVII, Lima, Institut français d'études andines - Fondo editorial de la Pontificia Universidad Católica del Perú, 2003, 882 p. (« Clásicos Peruanos »).

1 LA SORTIE des Procesos y Visitas de Idolatrías, Cajatambo Siglo XVII, édités par Pierre Duviols et publiés en 2003 par l'Institut français d'études andines et l'Université catholique du Pérou, représente un véritable événement. Il s'agit d'une nouvelle édition revue, corrigée et augmentée de Cultura andina y Represión ${ }^{1}$ publiée en 1986. Cet énorme corpus (près de 700 pages de documents d'archives de l'archevêché de Lima) contient les procès-verbaux des visites ecclésiastiques et des procès pour idolâtrie, menés à l'encontre des Indiens de la province de Cajatambo (sierra nord de Lima) dans la seconde moitié du XVII ${ }^{\mathrm{e}}$ siècle. Très attendu, ce livre magistral ouvre l'accès à des sources inédites sur l'organisation de la société locale, ainsi que sur la religion préhispanique et du début de l'ère coloniale lorsque le catholicisme s'imposa au Pérou. La valeur des ces textes ne trouve peut-être son équivalent que dans la fameuse relation en quechua des Ritos y Tradiciones de Huarochirí, traduite et éditée par Gerald Taylor ${ }^{2}$.

2 L'étude historique préliminaire est totalement renouvelée et enrichie par rapport à celle publiée dans Cultura andina y Represión. Pierre Duviols nous dresse un portrait précis de l'«Extirpation des idolâtries » dans la vice-royauté du Pérou. Sous le terme d'« Extirpation», l'auteur désigne l'institution qui a tenu lieu d'Inquisition pour les Indigènes et qui a organisé des visites ecclésiastiques et des procès pour idolâtrie et 
sorcellerie. S'il ne s'agit pas de minimiser son projet "pédagogique ", l'Extirpation, à travers sa " guerre anti-idolâtrique », incarna la partie répressive et négative de l'effort colonial de christianisation dans les Andes. Deux périodes historiques sont clairement distinguées. La première, entamée à la Conquête, s'étendit jusqu'en 1610. La seconde s'esquissa en 1610, devint efficace à partir de 1621 et se prolongea tout au long du XVII siècle. Les procès de Cajatambo s'inscrivirent au sein de cette seconde étape de l'évangélisation qualifiée de "Nouvelle Extirpation ", qui concerna principalement la sierra de Lima, archidiocèse qui connut la plus grande quantité de visites et de procès pour idolâtrie réalisés au Pérou à l'époque coloniale. L'auteur s'attarde sur les conditions d'émergence de cette «fille bâtarde de l'Inquisition». Il s'intéresse aux acteurs et aux enjeux politiques qui peuvent expliquer le renouveau des campagnes d'extirpation des idolâtries à partir de 1610. Pierre Duviols revient alors avec attention sur la biographie et sur le rôle joué par le curé de la paroisse de Huarochirí, Francisco de Avila, souvent considéré comme le père de la Nouvelle Extirpation. Dans son fameux « appel » de 1609 adressé à la Compagnie de Jésus, Avila dénonce la duplicité des fidèles de sa paroisse de San Damián. Il les accuse de continuer à pratiquer leurs rites païens tout en simulant un comportement de bons chrétiens. Sans nier la place occupée par ce prêtre, l'auteur montre que son influence ne doit pas être surestimée dans la genèse de la «Nouvelle Extirpation ». Le moteur politique déclencheur doit certainement être recherché dans la collusion entre l'archevêque Lobo Guerrero, ancien inquisiteur au Mexique et "champion de l'extirpation itinérante", et les pères jésuites, dont l'influence et le pouvoir s'étaient renforcés auprès de la cour d'Espagne depuis l'accession au pouvoir de Philippe III en 1598. C'est en 1610 que Lobo Guerrero créa la fonction du Visitador de idolatrías, juge ecclésiastique chargé de la répression des idolâtries. Une de ses missions consistait donc à visiter les paroisses d'Indiens afin de contrôler le travail d'évangélisation entrepris par les prêtres. Il s'agissait également de reprendre prise sur les ordres réguliers qui s'étaient retrouvés à la tête de nombreuses paroisses.

3 La région de Cajatambo, appartenant à l'archidiocèse de Lima, était bien connue des autorités de l'Église, puisque des campagnes ecclésiastiques y avaient déjà été menées dans le premier quart du XvII ${ }^{e}$ siècle. En effet, en 1617, lorsque s'amorce la Nouvelle Extirpation, la visite de l'Extirpateur Fernando de Avendaño avait déjà abouti à la " découverte » et à la crémation de plusieurs momies d'ancêtres auxquelles un culte était rendu - événement rappelé à maintes reprises dans les témoignages publiés dans cette édition. En 1621, le jésuite Hernández Príncipe se rendit à son tour à Cajatambo. On trouvera en annexe, des "rapports d'idolâtries» de ces deux religieux. Ces textes complémentaires au corpus permettent d'appréhender l'histoire de Cajatambo sur un demi-siècle. Quarante ans plus tard, entre 1656 et 1663, le visitador Noboa - curé de la paroisse de San Pedro de Ticllos à Cajatambo en 1651 - entreprit des prospections dans plusieurs villages du haut Pativilca (Cajatambo). Les minutes de douze procès pour idolâtries organisés à la suite de ses visites sont rapportées dans cet ouvrage. Ces documents sont tout à fait uniques. D'abord en raison de l'origine des informations fournies, directement recueillies auprès de la population locale par Noboa. Au cours de ces procès, femmes et hommes, accusés de s'adonner à des rites païens et diaboliques, vinrent faire leur déposition. Pour assurer leur défense, plaider leur innocence ou chercher à se disculper d'avoir participé à certains rituels païens, certains témoins dénoncèrent leurs voisins et les accusèrent de propagateurs d'idolâtries, dogmatizadores (dogmatiseurs) et hechiceros (sorciers). D'autres inculpés reconnurent les charges 
portées contre eux et se confessèrent alors. Ils indiquèrent les lieux de culte et la localisation de leurs "idoles", offrant de minutieuses descriptions des divers rites et sacrifices réalisés. D'ordinaire, la plupart des écrits se référant à la religion préhispanique ou à celle pratiquée par les Indiens à l'époque coloniale sont rédigés par des prêtres, acteurs du processus d'évangélisation, voire extirpateurs eux-mêmes. Ici, ce sont les principaux intéressés qui attestent des usages rituels locaux, même si les déclarations ont lieu dans une situation d'interlocution tout à fait spécifique, dans le cadre d'un tribunal et dans la position d'accusé ou de témoin à charge. On aurait peutêtre aimé trouver un lexique afin d'aider les personnes peu familières de l'espagnol andin à lire les actes de ces procès. En effet, ces textes comportent de nombreux termes en quechua qui ont déjà été intégrés, à cette époque, à l'espagnol local: mochar (vénérer), chacara (parcelle cultivée), cuies (cochons d'Inde), pircar (clôturer par un mur), etc. Un tel lexique aurait rendu ces textes, si passionnants, accessibles à un public sans doute plus large que celui qui s'y plongera véritablement.

Les Procesos y Visitas de Cajatambo nous fournissent une ethnographie inédite de la société rurale de cette région au milieu du $\mathrm{XVII}^{\mathrm{e}}$ siècle. Les témoignages ont notamment permis d'éclairer le fonctionnement du dualisme Huari-Llacuaz qui structurait les relations entre les ayllu (lignages) d'agriculteurs des vallées (les Huari) et ceux des éleveurs de la puna (les Llacuaz) dont Pierre Duviols avait fait la présentation dans l'édition de 1986 et qu'il avait analysé en détail dans un article de $1973^{3}$. Les descriptions relatives à l'organisation de la vie quotidienne au sein de ces villages andins sont d'une profusion de détails tout à fait remarquables. Y sont dépeints cultes propitiatoires, techniques divinatoires, rites de naissance, ou encore les différentes séquences des rites funéraires sur lesquels les procès s'étendent longuement. La plupart des chefs d'accusation imputés aux paroissiens de Cajatambo concernent l'exhumation de cadavres de chrétiens qui avaient été préalablement enterrés dans le cimetière ou dans l'église de la paroisse. Les corps étaient ensuite ramenés dans des cavités rocheuses (machais) où étaient conservés les momies de personnages considérés comme les fondateurs de lignage (malqui). Les visites ont donné lieu à des autodafés durant lesquels ces corps païens, "gentils ", récupérés par les prêtres après avoir obtenu les confessions des Indiens, étaient brûlés publiquement sur la place des villages. Ces sources exposent les méthodes employées par la Nouvelle Extirpation et les châtiments infligés aux apostats (obligations de servir à l'Église un an durant en portant une croix ou en gardant attachée autour du cou une corde en signe de pénitence, voire, pour les récidivistes, l'envoi pour quatre ans dans les galères du port du Callao, etc.).

5 L'importance de ces documents tient aussi au fait que les témoignages réunis viennent éclairer notre compréhension des coutumes funéraires et du culte des ancêtres précolombiens. Leur étude a d'ailleurs permis de reconstruire le mode de fonctionnement et les spécificités du culte préhispanique des ancêtres, tel que Pierre Duviols l'a mis au jour dans son article publié dans L'Homme en $1979^{4}$. Si les procès évoquent les malqui, ils font également référence aux huanca (ou guanca), doubles lithiques des ancêtres momifiés. Or, il s'agit pratiquement des seules sources coloniales dont nous disposons pour comprendre la nature du huanca et l'usage rituel auquel il donnait lieu. L'ancêtre, qui était censé avoir conquis le territoire avant de le borner, avait légué les terres arables et l'art de cultiver à ses descendants. À sa mort, ce héros civilisateur se dédoublait en deux éléments : sa dépouille, ultérieurement momifiée (malqui), et le fruit de sa lithomorphose, le huanca. Chaque noyau d'habitations 
possédait son huanca tutélaire. Il pouvait y en avoir plusieurs pour un même groupe social, correspondant à différents ancêtres pétrifiés. Ces pierres, situées au milieu des terrains cultivés, garantissaient et favorisaient le cycle agricole. Des offrandes et des sacrifices leur étaient offerts à différentes occasions dans un but propitiatoire, ainsi que ces procès nous le montrent. Au-delà de sa fonction fécondatrice, le huanca était un marcayoc, c'est-à-dire un protecteur du village et de ses habitants. Sa présence symbolisait l'occupation de l'espace, bornait le territoire sur lequel il se trouvait et légitimait la propriété du lieu. Les informations que l'on trouve dans ces documents offrent aussi de nombreuses pistes de recherche pour les études anthropologiques actuelles. Ainsi, l'usage et les fonctions attribués à certains monolithes (ramadero) durant les rites andins de fertilité des animaux au Pérou, s'inscrivent dans la tradition du huanca préhispanique. Le symbolisme attribué autrefois à l'ancêtre pétrifié huanca s'est déplacé de nos jours sur cette figure ambivalente du ramadero qui assure, à l'instar du huanca, un rôle de premier ordre dans le domaine de la fécondité et du bornage territorial ${ }^{5}$. Les procès nous renseignent également sur les recompositions sociales et religieuses qui se mirent en place au sein de la société indigène, un peu plus d'un siècle après la Conquête, notamment en ce qui concerne l'évolution coloniale du culte des ancêtres. Par exemple, il est intéressant d'observer que la crémation de certaines momies à Cajatambo par l'extirpateur Avendaño en 1617, ou par son successeur Hernández Príncipe dans les années 1620, n’a pas nécessairement supprimé toute vénération des ancêtres. En effet, on trouve des références de cultes rendus aux restes carbonisés de momies réchappées d'anciens autodafés. Ainsi, on peut observer l'évolution du rapport au corps et à la dépouille de l'ancêtre qui se produisit seulement au cours de trois ou quatre décennies. Ces procès montrent les dynamiques qui motivèrent le maintien, à Cajatambo, du culte des ancêtres. Pour être plus précise, et César Itier l'a démontré, il s'agit de comprendre les processus qui présidèrent à la revitalisation du culte ancestral alors même que d'autres entités de l'ancienne religion préhispanique, tel le soleil, étaient délaissées. Comme le signalèrent de nombreux témoins au cours des procès, le culte des momies était essentiellement réactivé par les caciques (curacas), principaux inculpés des procès. Or, leur pouvoir était traditionnellement légitimé par le lien qui les unissait au malqui, héros fondateur du village. Dans le nouvel ordre social colonial qui modifia leur emprise sur la population locale, il semble que les curacas cherchèrent à redéfinir les bases symboliques de leur autorité en entretenant les rites rendus aux momies ${ }^{6}$. Pour autant, la continuité des cultes ancestraux ne s'accompagnait pas systématiquement du rejet du message chrétien de la part des caciques et doit être analysée à la lumière des bouleversements qui découlèrent de la nouvelle configuration sociopolitique : accéder à des charges religieuses au sein de la société coloniale octroyait également prestige social et pouvoir politique. Cette vénération des ancêtres ne doit donc pas forcément être perçue comme une « résistance culturelle » à l'invasion espagnole, mais plutôt comme un moyen, parmi d'autres, de chercher à reconquérir un pouvoir affaibli par la domination coloniale.

6 En appendice de l'ouvrage, le lecteur trouvera la transcription paléographique d'un corpus de prières en quechua incluses dans les procès, traduites et annotées par César Itier et entièrement revues pour cette édition. La richesse de leur contenu permet également d'amplifier notre compréhension de la religion en place avant l'arrivée des Espagnols. Ces courtes oraisons, adressées à différentes entités du panthéon religieux préhispanique (soleil, pléiades, Huari, Libiac, malqui et guanca, etc.), sont 
essentiellement des demandes propitiatoires dans le domaine de la santé et de la fertilité humaine, animale et végétale.

7 On n'aura de cesse de rappeler la valeur exceptionnelle des sources contenues dans les Procesos y Visitas de Idolatrías, Cajatambo Siglo XVII, et d'en recommander vivement la lecture. Cette publication, essentielle à la connaissance de la société andine préhispanique et coloniale, s'inscrit dans les références indispensables pour tout chercheur andiniste. Elle intéressera aussi très certainement archéologues, historiens et anthropologues américanistes travaillant sur ces thématiques.

\section{NOTES}

1. . Pierre Duviols, ed., Cultura andina y Represión, Cuzco, CBC, 1986.

2. . Gerald Taylor, ed., Ritos y tradiciones de Huarochirí del siglo XVII, Lima, IFEA-BCRP - Universidad Ricardo Palma, 1999.

3. . Ce dualisme d'origine préhispanique était encore en vigueur à l'époque des visites d'idolâtries de Cajatambo dans la seconde moitié $d u x_{\text {XII }}$ e siècle. Les Huari étaient considérés comme les descendants des premiers occupants du territoire, héros civilisateurs engendrés par le dieu chtonien Huari, tandis que les Llacuaz, éleveurs de l'étage écologique plus élevé de la puna considérés comme les descendants du dieu de la foudre, de l'éclair et du tonnerre, Libiac, étaient des "étrangers ", issus des dernières conquêtes postérieures aux Huari. Ils demeuraient associés au monde de la nature sauvage et inculte. Pour plus de détails sur le système d'opposition complémentaire Huari-Llacuaz, voir l'article de Pierre Duviols, «Huari y Llacuaz. Agricultures y pastores: un dualismo prehispánico de oposición y complementariedad», Revista del Museo Nacional, Lima, 1973, 39 : 153-191.

4. .Pierre Duviols, «Un symbolisme de l'occupation, de l'aménagement de l'espace et de l'exploitation de l'espace. Le monolithe "huanca" et sa fonction dans les Andes préhispaniques ", L'Homme, 1979 (2) : 7-31.

5. . Pour plus de détails, je renvoie au chapitre consacré aux monolithes ramadero, in Valérie Robin, Miroirs de l'Autre vie : rites et représentations des morts dans les Andes sud péruviennes, thèse de doctorat en ethnologie, Université Paris X, 2002 : 287-307.

6. . César Itier, « Les caciques de Cajatambo et les cultes autochtones au milieu du XVII siècle », in Les autorités indigènes entre deux mondes. Solidarité ethnique et compromission coloniale, textes réunis par Bernard Lavallé, Paris, Université de la Sorbonne Nouvelle-CRAEC, 2004 : 147-157. 